\title{
The characteristics of bacterial pathogens in 15000 cases of children with respiratory tract infection in Eastern area.
}

\author{
Guiting Liu $^{\text {* }}$, Meiying Wang ${ }^{2}$, Kai Jiang ${ }^{1}$, Weiping Wang1, Weizhao Wang1 \\ ${ }^{1}$ Department of Pediatrics, Chang Yi People's Hospital, PR China \\ ${ }^{2}$ Department of Disinfection Supply Center, Chang Yi People's Hospital, PR China
}

\begin{abstract}
Objective: To understand the characteristics of bacterial pathogens in children with respiratory tract infection.

Methods: The clinical data of 15000 cases of children admitted to Children's Hospital because of respiratory tract infection for consecutive 9 years from November 2005 to October 2014 were collected for retrospective analysis.

Results: In 15000 cases of sputum specimens of children with respiratory tract infection, the first bacterial pathogens were Streptococcus pneumonia (12.79\%). In different years, different seasons, different ages of children with bacterial, the differences of detection rate had statistical significance (P<0.01). The rate of $3 \mathrm{y}$ old $\sim$ group was the highest, $\geq 5 \mathrm{y}$ old group was the lowest, and the difference was statistically significant $\left(\chi^{2}=92.83, P<0.001\right)$. In summer it was the highest, and autumn the lowest, the difference of which was statistically significant $\left(\chi^{2}=22.18, P<0.001\right)$. The positive rate of sputum bacterial culture in children who didn't receive antibiotics use before admission was higher than those who received antibacterial drugs $(\mathbf{P}<\mathbf{0 . 0 1})$.

Conclusion: Streptococcus pneumoniae is the most common bacterial pathogens that cause respiratory tract infection of children, followed by Haemophilus influenzae and Moraxelle catarrhalis. The detection rate of bacterial pathogens varies in different years and seasons and children of different ages. The course of the disease before admission and the course of antibiotic use outside hospital had an effect on the positive detection rate of bacteria.
\end{abstract}

Keywords: Respiratory tract infection, Bacteria, Pathogens, Children.

Accepted on December 1, 2017

\section{Introduction}

In worldwide, respiratory infection is one of the most common pediatric diseases, and according to the statistics of WHO, respiratory tract infection is the second leading cause of death at the age of under 5, followed by premature birth. In developed countries, the main pathogens was virus, while in developing countries it's mainly bacteria $[1,2]$. It is pointed out by the guidelines for the management of community-acquired pneumonia in children in 2013 that the common pathogens which cause community-acquired pneumonia in children are bacteria, viruses, mycoplasma, chlamydia, in addition, fungi and protozoa [3]. Among them, the bacteria mainly include Streptococcus pneumoniae (SP), Haemophilus influenzae (HI), Staphylococcus aureus (SA), Moraxelle catarrhalis (MC), Escherichia coli (E. coli), Klebsiella pneumoniae (KPN) and so on.

Common bacteria that cause hospital acquired pneumonia are E. coli, KPN, Pseudomonas aeruginosa (Pseudomonas aeruginosa PA), Bauman Acinetobacter (Acinetobacter baumannii, $\mathrm{AB}$ ) in gram negative bacilli and SA, SP,
Enterococcus faecalis and Enterococcus faecium of Enterococcus in gram positive cocci [4]. In 2000, Toikka et al. [5] reported that in 126 cases of children with pneumonia, 54\% were bacterial infection. The results of a study in Finland showed that $85 \%$ of children with lower respiratory tract infection could have clear etiological diagnosis, and bacterial infection rate was 53\% [6]. Domestic reports indicated that the positive detection rate of bacteria in children with respiratory tract infection was $18.30 \% \sim 56.82 \%$ [7-11]. Therefore, bacterial infection is an important pathogen of respiratory tract infection, and its detection rate is affected by geographical environment, season, age, disease constitution, antimicrobial use, drug resistance and other factors $[12,13]$. Brad et al. also reported that bacteriological diagnosis and antibiotic resistance surveillance are indispensable in the effective management of Lower Respiratory Tract Infections (LRTIs) [14]. Through the analysis on bacterial etiology of children with communityacquired respiratory tract infection admitted to Children's Hospital for consecutive $9 \mathrm{y}$, this study is to understand the epidemiological characteristics of bacterial etiology in children with respiratory tract infection in this local area. 


\section{Data and Methods}

\section{Research subjects}

15000 cases of children admitted to Children's Hospital because of respiratory tract infection from November 2005 to October 2014 were collected as research subjects. According to the season the groups were divided into four groups: 4023 cases of spring group (2 4 months), 3717 cases of summer group (5 7 months), 3498 cases of autumn group $(8 \sim 10$ months), and 3762 cases of winter group (November to January of next year). There were 4772 cases of children with the use of antibiotics outside hospital to divide three groups, including 2928 cases of antibiotic use time outside hospital $\leq 3$ d, 1280 cases of $4 \sim 7 \mathrm{~d}$, and 564 cases of $>7 \mathrm{~d}$. There were total of 11370 cases that had course related data in medical history, according to the course of disease outside hospital to divide three groups: 10674 cases of $<1$ month group, 559 cases of $1 \sim 3$ months group, 137 cases of $>3$ months group.

\section{Collection of sputum samples}

The sputum was collected at the admission of $24 \mathrm{~h}$, and the aseptic suction tube was inserted into the child's nasal cavity of $7 \sim 8 \mathrm{~cm}$ until under the pharynx, 1 2 $\mathrm{ml}$ secretions induced to be absorbed were placed in a sterile saline test tube and submitted within half an hour. The collected sputum specimens were first smeared and examined by microscopy, and squamous cells $<10 /$ low magnification view, white blood cells $>25 /$ low magnification view were regarded as qualified, and the unqualified were re-collected or discarded.

\section{Detection of sputum samples}

The $1 \mathrm{ml}$ sputum was added into $75 \mu \mathrm{L}$ phlegm digestive juice (including two sulfur threonic sugar $0.1 \mathrm{~g}$, muriate $0.02 \mathrm{~g}$, sodium chloride $0.78 \mathrm{~g}$, disodium hydrogen phosphate $0.112 \mathrm{~g}$, monopotassium phosphate $0.02 \mathrm{~g}$ ), after $0.5 \mathrm{~h}$ incubation in $35^{\circ} \mathrm{C}$ incubator, the sputum was taken out with a sterile inoculation ring, and were inoculated in Columbia blood agar plates and chocolate plates, then put into an incubator containing $5 \% \sim 8 \% \mathrm{CO}_{2}$ for $18 \sim 24 \mathrm{~h}$ incubation. According to the characteristics of colony on the culture medium, gram staining, microscope observation, biochemical reaction and other methods, the bacteria were identified.

\section{Statistical analysis}

SPSS17.0 statistical software packet was used for statistical processing and analysis, count data were expressed by the number of cases and the percentage $(\%), \chi^{2}$ test, trend $\chi^{2}$ test was adopted for comparison between groups, and the comparison of the rates among multi groups was compared by the Chi square method. $\mathrm{P}<0.05$ was believed as statistically significant difference.

\section{Result}

The male: female ratio was 1.67:1. The youngest child was 29 $\mathrm{d}$, and the oldest $15 \mathrm{y}$ and 10 months, including 4578 cases of $<6$ months, 2594 cases of 6 months $\sim, 2610$ cases of 1 y old , 1271 cases of 2 y old $\sim, 2246$ cases of 3 y old $\sim$, and 1701 cases of $\geq 5$ y old.

\section{The total bacterial detection rate in $9 y$}

In 15000 cases of samples, 3950 cases had positive bacteria test, and the positive rate was $26.32 \%$. Among them, the mixed infection rate of two or more than two was $2.33 \%(350 / 15000)$. A total of 4286 strains were detected, and the detection rate of SP was the highest, followed by HI, MC, SA, E. coli, KPN. In 350 cases of mixed infection, the top 3 were: SP merged with HI $21.7 \%$ (76/350), SP merged with MC 12.0\% (42/350), and HI merged with MC 5.7\%(20/350).

\section{The bacterial detection situation in each season}

The bacterial detection rate of each season as spring, summer, autumn winter were in turn $26.93 \%$ (1083/4023), $27.51 \%$ (1022/3717), 23.28\% (814/3498), 27.34\% (1028/3762). In summer it was the highest, and autumn the lowest, the difference of which was statistically significant $\left(\chi^{2}=22.18\right.$, $\mathrm{P}<0.001)$. The detection rates of SP, HI in the two seasons of spring and summer were both higher; the detection rates of SP, SA in autumn were higher; the detection rates of SP, MC in winter were higher. For single bacteria, the detection rates of SP in four seasons were all higher than that of other bacteria, and the highest was in winter and the lowest in spring; the highest detection rate of $\mathrm{HI}$ was in spring and the lowest in autumn; the highest detection rate of MC was in winter and the lowest in autumn; detection rate of $E$. coli in spring was the highest, the lowest in summer; the highest detection rate of PA was in autumn, and the lowest in winter; in the summer $A B$ detection rate was the highest, and the lowest in winter; the difference in detection rate of SA, KPN in the four seasons was not significant (Table 1).

\section{Detection situation of bacteria in different age groups}

The bacterial detection rates in all ages such as $<6$ months, 6 months $\sim, 1$ y old $\sim, 2$ y old $\sim, 3$ y old,$\geq 5$ y old were respectively $27.95 \%$ (1278/4578), $27.83 \%$ (722/2594), $27.20 \%$ (710/2610), 20.22\% (257/1271), 29.21\% (656/2246), 19.05\% (324/1701), of which the rate of $3 \mathrm{y}$ old group was the highest, $\geq 5$ y old group was the lowest, and the difference was statistically significant $\left(\chi^{2}=92.83, \mathrm{P}<0.001\right)$.

\section{The influence of antibiotics use before admission on bacterial detection}

Among the 15000 cases of children, 5721 cases had related data whether antibiotics were used before admission, including 4772 cases $(83.41 \%)$ with antibiotics use before admission. The bacteria detection in sputum culture of children without antibiotics use before admission was 33.29\% (316/949), which 
was higher than that of the children with antibiotics use, accounting for $20.93 \%(999 / 4772)(\mathrm{P}<0.001)$. The use course of antibiotics before admission also had impact on the composition of bacteria: the difference in the detection rate of SA in the three groups such as use course $\leq 3 \mathrm{~d}, 4 \sim 7 \mathrm{~d},>7 \mathrm{~d}$ was statistically significant $(\mathrm{P}<0.05)$. Among them, the detection rate of $\mathrm{AB}$ in $4 \sim 7 \mathrm{~d}$ group was higher than that of $\leq 3 \mathrm{~d}$ group, the difference of which was statistically significant. Under the condition of same use course of antibiotics, the positive detection rates of SP in the groups with different use courses of antibacterial drugs were all the highest (Table 2).

\section{The influence of disease course before admission on bacterial detection situation}

11370 children with course related data before admission collected were analysed, showing that the positive rate of bacteria in sputum culture of children in 3 groups such as course outside hospital $<1$ month group, 1 3 months group, $>3$ months group were respectively $29.47 \%$ (3146/10674), $34.35 \%$ (192/559). 33.58\% (46/137), the difference of which was statistically significant $\left(\chi^{2}=7.00, \mathrm{P}=0.03\right)$. The positive rate of sputum culture in 1 3 months group was higher than that in $<1$ month group, the difference of which was statistically significant.

The disease course outside hospital also affected the composition of detected bacteria: in disease course outside hospital $<1$ month group, 1 3 months group, $>3$ months group, the difference in detection rate of $\mathrm{SP}, \mathrm{MC}$ and $\mathrm{AB}$ was statistically significant $(\mathrm{P}<0.05)$. Among them, the detection rates of SP and $\mathrm{MC}$ in disease duration 1 3 months group were higher than that of disease duration $<1$ month group; detection rate of $\mathrm{AB}$ in disease duration $>3$ months group was higher than that of $<1$ month group; under the condition of same disease course before admission, the positive detection rates of SP were all higher than that of other bacteria (Table 3).

Table 1. The detection situation of 8 common bacteria in different seasons (case (\%)).

\begin{tabular}{|c|c|c|c|c|c|c|}
\hline Bacterial species & Spring $(n=4023)$ & Summer $(n=3717)$ & Autumn $(n=3498)$ & Winter $(n=3762)$ & $x^{2}$ value & $P$ value \\
\hline SP & $434(10.74)$ & $473(12.70)$ & 404 (11.52) & $613(16.25)$ & 60.49 & $<0.001$ \\
\hline $\mathrm{HI}$ & $324(8.06)$ & $262(7.05)$ & $67(1.92)$ & $100(2.66)$ & 224.48 & $<0.001$ \\
\hline MC & $123(3.06)$ & $100(2.69)$ & $77(2.20)$ & $137(3.64)$ & 14.29 & $<0.001$ \\
\hline SA & $108(2.69)$ & $95(2.56)$ & $88(2.52)$ & $72(1.91)$ & 5.69 & 0.13 \\
\hline E. coli & $63(1.57)$ & $29(0.78)$ & $44(1.26)$ & $53(1.41)$ & 10.58 & 0.014 \\
\hline KPN & $38(0.95)$ & $36(0.97)$ & $43(1.23)$ & $42(1.12)$ & 1.88 & 0.60 \\
\hline PA & $23(0.57)$ & $33(0.89)$ & $54(1.54)$ & $21(0.56)$ & 26.7 & $<0.001$ \\
\hline$A B$ & $20(0.50)$ & $38(1.02)$ & $23(0.66)$ & $8(0.21)$ & 21.71 & $<0.001$ \\
\hline$x^{2}$ value & 1208.47 & 1350.50 & 1113.15 & 2160.30 & & \\
\hline$P$ value & $<0.001$ & $<0.001$ & $<0.001$ & $<0.001$ & & \\
\hline
\end{tabular}

Note: SP: Streptococcus pneumoniae; HI: Haemophilus influenzae; MC: Moraxelle catarrhalis; SA: Staphylococcus aureus; E. coli: Escherichia coli; KPN: Klebsiella pneumoniae; PA: Pseudomonas aeruginosa; AB: Bauman Acinetobacter.

Table 2. The detection situation of 8 common bacteria in different use courses of antibiotic (case (\%)).

\begin{tabular}{|c|c|c|c|c|c|}
\hline $\begin{array}{l}\text { Bacterial } \\
\text { species }\end{array}$ & $\begin{array}{l}\leq \quad 3 \\
(n=2928)\end{array}$ & $\begin{array}{l}4 \sim 7 \\
(n=1280)\end{array}$ & $\begin{array}{l}>7 \\
(n=564)\end{array}$ & $x^{2}$ value & $P$ value \\
\hline SP & $375(12.81)$ & 177 (13.83) & $84(14.89)$ & 2.16 & 0.34 \\
\hline $\mathrm{HI}$ & $142(4.85)$ & $62(4.84)$ & $23(4.08)$ & 0.65 & 0.72 \\
\hline MC & $83(2.83)$ & $22(1.72)$ & $13(2.30)$ & 4.67 & 0.09 \\
\hline SA & $96(3.28)$ & $16(1.25) \mathrm{a}$ & $7(1.24) \mathrm{a}$ & 19.20 & $<0.001$ \\
\hline E. coli & $33(1.13)$ & $16(1.25)$ & $13(2.30)$ & 5.15 & 0.08 \\
\hline KPN & $31(1.06)$ & $8(0.63)$ & $5(0.89)$ & 1.84 & 0.39 \\
\hline PA & $24(0.82)$ & $13(1.02)$ & $9(1.60)$ & 3.03 & 0.22 \\
\hline$A B$ & $1(0.03)$ & $7(0.55) \mathrm{a}$ & $2(0.35)$ & 11.85 & 0.001 \\
\hline
\end{tabular}

\begin{tabular}{llll}
\hline$X^{2}$ value & 1080.73 & 606.45 & 267.72 \\
\hline$P$ value & $<0.001$ & $<0.001$ & $<0.001$ \\
\hline
\end{tabular}

Note: a showed that compared with $\leq 3 \mathrm{~d}$ group, $\mathrm{P}<0.0125$ (chi square segmentation method was used for comparison among multi groups, the test level was adjust to 0.0125). SP: Streptococcus pneumoniae; HI: Haemophilus influenzae; MC: Moraxelle catarrhalis; SA: Staphylococcus aureus; E. coli: Escherichia coli; KPN: Klebsiella pneumoniae; PA: Pseudomonas aeruginosa; AB: Bauman Acinetobacter.

Table 3. The detection situation of 8 common bacteria in different disease courses (cases (\%)).

\begin{tabular}{llllll}
\hline $\begin{array}{l}\text { Bacterial } \\
\text { species }\end{array}$ & $\begin{array}{l}<1 \quad \text { month } \\
(\mathbf{n = 1 0 6 7 4 )}\end{array}$ & $\begin{array}{l}\mathbf{1} 3 \\
\text { months } \\
(\mathbf{n = 5 5 9 )}\end{array}$ & $\begin{array}{l}>3 \text { months } \\
(\mathbf{n = 1 3 7 )}\end{array}$ & $\mathrm{x}^{2}$ value & P value \\
\hline $\mathrm{SP}$ & $1352(12.67)$ & $95(16.99)^{\mathrm{a}}$ & $24(17.52)$ & 11.42 & 0.003 \\
\hline $\mathrm{HI}$ & $564(5.28)$ & $21(3.76)$ & $8(5.84)$ & 2.62 & 0.27 \\
\hline
\end{tabular}




\begin{tabular}{llllll}
\hline MC & $364(3.41)$ & $43(7.69)^{\mathrm{a}}$ & $9(6.57)$ & 30.97 & $<0.001$ \\
\hline $\mathrm{SA}$ & $331(3.10)$ & $13(2.33)$ & $1(0.73)$ & 3.27 & 0.19 \\
\hline E. coli & $145(1.36)$ & $7(1.25)$ & 0 & 1.30 & 0.58 \\
\hline $\mathrm{KPN}$ & $123(1.15)$ & $7(1.25)$ & $1(0.73)$ & 0.11 & 0.95 \\
\hline $\mathrm{PA}$ & $131(1.23)$ & $10(1.79)$ & $2(1.46)$ & 1.82 & 0.35 \\
\hline $\mathrm{AB}$ & $61(0.57)$ & $5(0.89)$ & $3(2.19)^{\mathrm{a}}$ & 5.97 & 0.047 \\
\hline $\mathrm{X}^{2}$ value & 3421.55 & 277.42 & 78.08 & & \\
\hline P value & $<0.001$ & $<0.001$ & $<0.001$ & & \\
\hline
\end{tabular}

Note: a showed that compared with $<1$ month group, $\mathrm{P}<0.0125$ (chi square segmentation method was used for comparison among multi groups, the test level was adjust to 0.0125). SP: Streptococcus pneumoniae; HI: Haemophilus influenzae; MC: Moraxelle catarrhalis; SA: Staphylococcus aureus; E. coli: Escherichia coli; KPN: Klebsiella pneumoniae; PA: Pseudomonas aeruginosa; AB: Bauman Acinetobacter.

\section{Conclusion}

The surveillance of sputum bacterial etiology in children with respiratory tract infection admitted to the department of respiration in children's hospital for consecutive 9 y was carried out, a total of 15000 specimens were collected, including 3950 cases of positive specimens in sputum culture, and the total positive rate was $26.32 \%$, lower than $28.63 \%$ in Guangxi, $56.82 \%$ in Guangzhou, $35.38 \%$ in Sanya, $28.10 \%$ in Shandong, but higher than $18.30 \%$ in Hunan [7-10,15-19], indicating that in various regions, the detection rate of respiratory tract bacterial pathogen had differences.

This study suggested that in the total rate of bacteria in the four seasons such as spring, summer, autumn and winter, the highest detection rate was in summer and the lowest in autumn, indicating that the season had a certain influence on the detection rate of bacteria in children with respiratory tract infections. In the four seasons of spring, summer, autumn and winter, detection rate of SP was the top one, and the highest detection rate was in winter and the lowest in spring, which were consistent with the reports from Cai et al. [16] and Huang et al. [20]. The detection rate of E. coli was highest in spring and lowest in summer; the detection rate of PA was highest in autumn and lowest in winter; the detection rate of $\mathrm{AB}$ was highest in summer and lowest in winter, suggesting that the distribution and kind of pathogenic bacteria in children with respiratory tract infection in different seasons were different. The detection rate of bacteria in children with respiratory tract infection at different ages is also different. In each age group of $<6$ months, 6 months $\sim, 1$ y old $\sim, 2$ y old $\sim, 3$ y old $\sim$ and $\geq 5$ y old, the positive detection rate of bacterial was the highest in 3 y old $\sim$ group, followed by 6 months group, $<6$ months group, and the lowest in $\geq 5$ y old group, which showed a significant difference. As a result, the probability of bacterial infection in children under $1 \mathrm{y}$ old and $3 \sim 5 \mathrm{y}$ old were the highest, which was related to respiratory and systemic specific and nonspecific immune dysfunction in children of this age group. In addition, children of $3 \sim 5 \mathrm{y}$ old are in the nursery period, the susceptible environment of kindergartens and immune function which have not been well developed yet cause it prone to bacterial infection of respiratory tract. In all age groups, detection rate of SP come first, especially in the age group 3 5 y old, it was the highest and the lowest in $<6$ months group, which were basically consistent with the reports from Cai et al. [19] and Sun et al. [21-23]. Previous reports have suggested that $\mathrm{HI}$ and $E$. coli infections are mainly seen in children under 1 y old $[20,23,24]$. This study showed that HI was detected in all age groups with high incidence in 6 months $\sim$ group, followed by 1 y old group and $<6$ months group, and E. coli, SA, KPN, PA, AB had high incidence in $<6$ months group. All of the above bacteria were more common in hospital acquired infections, and the results of this study showed that under 1 years old, especially in $<6$ months group, it's more common, which may be related to more susceptible to infection due to the immature development of specific and non-specific immune function of this age group in the early stage of life, and inappropriate adaptation to the external environment. Thus, the work of strengthening the health of children and prevention of infection in this age group is particularly important, and when it is found in clinic that respiratory infections occur in children of this age group, especially severe infection, antimicrobial agents may be considered for the above bacteria.

Previous reports have confirmed that the detection rate of SA in $3 \sim 7 \mathrm{~d}$ course of antibiotic use outside hospital is obviously higher, and the detection rate of SP in $<3 \mathrm{~d}$ course of antibiotic use outside hospital is obviously higher [13]. The data in this study showed that, detection rate of sputum bacterial culture in children without antibiotics use before admission (33.29\%) was higher than those with antibiotics use $(20.93 \%)$. There are two possibilities for this result, one is the treatment of antibiotics before admission produces effective containment of bacterial infectious diseases, in addition, it may be due to the use of antibiotics to some extent causes bacterial culture difficulties, resulting in false negative. The detection rate of SA in use course of antibiotics $\leq 3 \mathrm{~d}$ group (3.28\%) was higher than that in more than $3 \mathrm{~d}$ group, which was inconsistent with the above reported [13], but it was consistent with the report of Sun et al. [23] in this research group, which might have something to do with different ages of the study. The detection rate of $\mathrm{AB}$ in group of antibiotic use course $4 \sim 7 \mathrm{~d}$ before admission was higher than that of less than $3 \mathrm{~d}$ group, suggesting that for different bacteria, rational antibiotic treatment course of outpatient may be more effective to decrease the infection rate of respiratory tract, meanwhile, it may also partly explain why $A B$ is mostly multi resistant bacteria.

This study also showed that the difference in positive detection rate of sputum culture bacteria in disease course outside hospital $<1$ month group, 1 3 months group, $>3$ months group was statistically significant. The course of disease also affected the composition of bacteria: in children of disease course 1 3 months, the detection rate of SP and MC was higher than that in $<1$ month group; the detection rate of $\mathrm{AB}$ in children of disease course $>3$ months was higher than that in $<1$ months group. The above results suggested that the positive detection rates of $\mathrm{SP}, \mathrm{MC}$ and $\mathrm{AB}$ showed an increase trend with the 
prolongation of the disease duration; the differences in the detection rates of different bacterial species in different disease course groups were considered to be related to the biological characteristics of bacteria, the use of antibiotics before admission and secondary infection. The specific reasons still need further study.

In conclusion, Streptococcus pneumoniae is the most common bacterial pathogens that cause respiratory tract infection of children, followed by Haemophilus influenzae and Moraxelle catarrhalis. The detection rate of bacterial pathogens varies in different years and seasons and children of different ages. The course of the disease before admission and the course of antibiotic use outside hospital had an effect on the positive detection rate of bacteria.

\section{Limitations}

Several limitations of this study should be considered. Firstly, this research was a cross-sectional study, further studies are needed to unravel this. Secondly, the sample size is not big enough. However, the study setting is a modern, high level comprehensive medical institution with sophisticated clinical diagnosis facilities and medical record management. Thus, the data used can be deemed reliable.

\section{References}

1. Liu L, Johnson HL, Cousens S. Global, regional, and national causes of child mortality: an updated systematic analysis for 2010 with time trends since 2000. Lancet 2012; 37: 2151-261.

2. World Health Organization (WHO). Indonesia: Health Profile. WHO Media Centre, Geneva, Switzerland 2014.

3. Wang L, Deng L, Lu Q. Guidelines for the management of community acquired pneumonia in children. Chinese $\mathrm{J}$ Pediatr 2013; 51: 745-752.

4. Chen H, Dong Z, Hong J. Management program of hospital acquired pneumonia in children (2010 Edition). Chinese J Pediatr 2011; 49: 106-115.

5. Toikka P, Irjala K, Juven T. Serum procalcitonin, C-reactive protein and interleukin- 6 for distinguishing bacterial and viral pneumonia in children. Pediatr Infect Dis J 2000; 19: 598-602.

6. Juvén T, Mertsola J, Waris M. Etiology of community acquired pneumonia in 254 hospitalized children. Pediatr Infect Dis J 2000; 19: 293-298.

7. Tan P, Tang L, Long X. Analysis on pathogens specimens and drug resistance of 325 cases of children with respiratory tract infection. J Nat Youjiang Med Coll 2014; 36: 609-611.

8. Liang Z, Kuang L, Xie Y. Pathogenic bacteria and drug sensitivity analysis of respiratory tract infection in childrens hospital. Int J Lab Med 2014; 35: 1445-1446.

9. Jiang Z, Peng J, Gu M. Analysis of pathogens in 1410 cases of children with respiratory tract infections. Chinese J Infect Control 2013; 12: 129-131.
10. Bian C. Analysis on drug resistance of bacteria in childrens respiratory tract infection. Med Exam 2013; 20: 110-111.

11. Xu L. Analysis on epidemiological characteristics and drug resistance of respiratory tract infections in children in Haikou. Med Sci Chongqing 2014; 4: 1803-1805.

12. Ji W, Chen Z, Zhou W. Etiological study of hospitalized children with acute respiratory tract infections in Eastern during 2005-2011. Chinese J Prev Med 2013; 47: 497-503.

13. Wang Z, Ji W, Guo H. Comparative study of bacterial pathogens constitution and drug resistance in childrens community and hospital acquired pneumonia. Chinese J Prev Med 2011; 45: 211-216.

14. Brad GF, Sabau I, Boia M. Trends in bacterial pathogens of lower respiratory tract infections in children. Timisoara Med J 2011; 61: 193-198.

15. Chen R, Zhong J. Bacterial flora distribution and drug sensitivity analysis of respiratory tract infections in children in Sanya area. Hainan Med 2012; 23: 102-104.

16. Rowensztein H, Demirdjian G, Rodrguez J. Carga de enfermedady costos asociados a las internaciones por infection respiratoria aguda en ni.os. Arch Argent Pediatr 2007; 105: 5-11.

17. Sinaniotis CA, Sinaniotis AC. Community-acquired pneumonia in children. Curr Opin Pulm Med 2005; 11: 218-225.

18. Zhao M, Wu Q, Wu C. Etiological detection and analysis of children with acute lower respiratory tract bacterial infection in Kunming area. J Shandong Med 2009; 49: 97-98.

19. Cai L, Ji W, Sun H. Analysis on bacteria constituent ratio and drug resistance of pharyngeal aspirate in children with pneumonia in Eastern. J Clin Pediatr 2013; 31: 1029-1033.

20. Huang L, Ji W, Wu J. Analysis on pathogens bacteria detection of extended spectrum $\beta$-lactamase produced by children with lower respiratory tract infection. J Pract Pediatr Clin 2008; 23: 1740-1742.

21. Spaniol V, Troller R, Aebi C. Physiologic cold shock increases adherence of Moraxella catarrhalis to and secretion of interleukin 8 in human upper respiratory tract epithelial cells. J Infect Dis 2009; 200: 1593-1601.

22. Sun H, Zhou W, Ji W. Correlation analysis on Mora M. infection and climatic factors in hospitalized children with lower respiratory tract infections in Eastern. J Clin Pediatr 2014; 32: 524-527.

23. Sun Q, Chen Z, Huang L. Pathogenic distribution and drug resistance analysis on hospitalized children with Sun Qiufeng, Chen Zhengrong, Huang Li. Pathogenic bacteria distribution and drug resistance of lower respiratory tract infection in Eastern from 2008 to 2012. Chinese J Clin Infect Dis 2014; 7: 39-44.

24. Wu J, Ji W, Tao Y. Analysis of the distribution and drug resistance of Haemophilus influenzae in childrens respiratory tract infections in Eastern during 2006-2007. J Clin Pediatr 2010; 28: 131-134. 


\section{*Correspondence to}

\section{Liu Guiting}

Department of Pediatrics

Chang Yi People's Hospital

PR China 